\title{
O SISTEMA ÚNICO DE SAÚDE E O DESAFIO DA GESTÃO REGIONALIZADA E CONTRATUALIZADA
}

\author{
The Unified Health System and the challenge of regionalized and contractualized \\ management
}

\section{El Sistema Único de Salud y el desafío de la gestión por regiones y de contratos}

\author{
Neusa Goya (Lattes) \\ Centro Universitário Christus - UNICHRISTUS - Fortaleza - (CE) - Brasil
}

Luiz Odorico Monteiro de Andrade (Lattes)

Fundação Oswaldo Cruz - FIOCRUZ - Fortaleza - (CE) - Brasil

\begin{abstract}
RESUMO
Objetivo: Analisar a regionalização da saúde, com ênfase no uso de diferentes tipos de modalidades de gestão e seus efeitos na garantia do direito à saúde. Métodos: Pesquisa qualitativa, cartográfica de ancoragem deleuzeana, recortada pela experiência do Ceará, em duas camadas investigativas, estadual, de 2013 a junho de 2015, com entrevistas de 23 gestores estaduais de saúde, abordando sua institucionalização; e na Região de Saúde Sobral, de fevereiro a setembro de 2016, discutindo os tipos de gestão adotados em unidades-referência públicas, com entrevistas de 14 gestores, 11 profissionais e 12 usuários. A análise dos discursos foi de abordagem foucaultiana e de autores da saúde coletiva. Resultados: A regionalização constituiu-se como estratégia da reforma da saúde, no Ceará, desde 90, institucionalizando diferentes modalidades de gestão, por meio de Consórcios Públicos de Saúde e Organização Social, operadas pelo mecanismo contratual de serviços de saúde. Conformou uma gestão regionalizada e contratualizada por resultados, em engate das dimensões jurídica à assistencial, com efeitos de verdade ao direito à saúde, restrito aos itens contratados e pagos, esboçando um padrão de cobertura de serviços. Considerações Finais: O acoplamento da contratualização à regionalização mostrou-se potente à modelagem do Sistema Único de Saúde pelo ideário da Cobertura Universal de Saúde, institucionalizando o deslocamento do integral e universal para o parcial e focal; do público para a privatização da gestão de seus equipamentos, mercantilização da saúde como bem de consumo e não de direito social e empresariamento dos modos de sua produção.
\end{abstract}

Descritores: Sistema Único de Saúde; Gestão em saúde; Regionalização; Cartografia; Consórcios de Saúde; Organização Social.

\section{ABSTRACT}

Objective: To analyze the regional health planning, with emphasis on the use of different types of management modalities and their effects on the guarantee of the right to health. Methods: Qualitative, cartographic study based on Deleuzean concepts, addressing the experience of Ceará with use of two investigative layers, the state, from 2013 to June 2015, with interviews of 23 state health managers, ddressing their institutionalization; and in the Sobral Health Region, from February to September 2016, discussing the types of management adopted in public referral units, with interviews of 14 managers, 11 professionals and 12 users. The discourse analysis was based on the Foucauldian approach and authors on the field of collective health. Results: Regionalization has become a strategy for the health care reform in Ceará since 1990, and institutionalized different management modalities, by means of the Public Consortia of Health and Social Organization, operated by the contractual mechanism of health services. This has established a regionalized management, contractualized by results, coupling the legal and care dimensions, with real effects to the right to health, restricted to contracted and paid items, and outlining a pattern of service coverage. Final considerations: Coupling contractualization with regionalization proved to be potent in modeling the Unified Health System on the Universal Health Coverage ideology, by institutionalizing the shift from comprehensive and universal to partial and focal, and from the public to privatizing the management of its equipment; the commodification of health care as consumer goods rather than a social right, and the managerial approach to its means of production.

Descriptors: Unified Health System; Health Management; Regional Health Planning; Geographic Cartography; Health Consortia; Social Organization.

Este artigo foi selecionado, corrigido e aprovado pela Comissão Científica do Fórum Internacional de Sistemas Universais de Saúde, seguindo suas normas e formatação. 


\section{RESUMEN}

Objetivo: Analizar la regionalización de la salud con énfasis para el uso de distintos tipos de modalidades de gestión y sus efectos para la garantía del derecho a la salud. Métodos: Investigación cualitativa, cartográfica de ancoraje deleuzeana, dividida por la experiencia de Ceará en dos camadas investigativas, la estadual entre 2013 y junio de 2015 con entrevistas de 23 gestores estaduales de salud sobre la institucionalización; y en la Región de Salud Sobral entre febrero y septiembre de 2016 con la discusión de los tipos de gestión adoptados en las unidades-referencia públicas con entrevistas de 14 gestores, 11 profesionales y 12 usuarios. Para el análisis de los discursos se usó el abordaje de Foucault y de autores de la salud colectiva. Resultados: La regionalización se constituyó en la estrategia de la reforma de salud en Ceará desde los 90 institucionalizando distintas modalidades de gestión a través de Consorcios Públicos de Salud y Organización Social, operadas por el mecanismo contractual de los servicios de salud. Resultó una gestión regionalizada y de contratos por resultados, en enganche con las dimensiones jurídica hasta la de la asistencia, con efectos verdaderos al derecho a la salud, restricto a los ítems contratados y pagados esbozando un patrón de cobertura para los servicios. Consideraciones Finales: El acoplamiento de contratos con la regionalización se mostró potente para el modelado del Sistema Único de Salud por el ideario de la Cobertura Universal de Salud institucionalizando el desplazamiento del integral y universal para el parcial y focal, del público para la privatización de la gestión de sus equipos, la mercantilización de la salud así como del consumo y no del derecho social y empresarial de los modos de su producción.

Descriptores: Sistema Único de Salud; Mapeo Geográfico; Consorcios de Salud; Organización Social.

\section{INTRODUÇÃO}

No Brasil, o Sistema Único de Saúde (SUS) instituiu o direito social à saúde de acesso universal, integral e público, em configuração institucional e legal de um regime de proteção social, definido pela modalidade de seguridade. Sua organização e funcionamento devem ser descentralizados, mediante uma rede regionalizada e hierarquizada de serviços de saúde. Como estratégia internacional para a organização e integração de serviços, em Sistemas Nacionais de Saúde, a regionalização é referida como caminho potente à consecução dos princípios da integralidade e da universalidade do acesso ${ }^{(1)}$.

No Brasil, estão instituídas quase quinhentas Regiões de Saúde ${ }^{(2)}(R S)$, sinalizando a centralidade desse modo regionalizado de governar o SUS. Entretanto, apesar disso, a integralidade e a universalidade do acesso ainda permanecem invisíveis na sociedade brasileira ${ }^{(3-6)}$, problematizando o processo de regionalização e seus efeitos na garantia do direito à saúde.

Em diálogo com a instituição do SUS e seu modo de governar regionalizado, outras proposições têm atravessado sua organização e funcionamento, produzindo paradoxos relacionados à sua constituição como Sistema público, universal e integral.

Uma delas refere-se a Universal Health Coverage, ou Cobertura Universal de Saúde (CUS), articulada pela Organização Mundial de Saúde (OMS), com o apoio da Fundação Rockfeller e do Banco Mundial(7-9) Em 2014, a CUS foi adotada pela $53^{\text {a }}$ reunião do Conselho Diretor da Organização Pan-Americana da Saúde (OPAS). Carissa Etienne, Diretora da OPAS à época, declarou que "Achieving universal health coverage is a moral imperative"(10) $e$ que a "History suggests that Latin America can lead the way" ${ }^{(10)}$. Nesse mesmo rumo, outros autores sinalizaram que "Latin America is a laboratory to study the mechanics of implementing UHC"(8)

Porém, o uso do termo Universal Health Coverage merece atenção, considerando suas diferentes possibilidades de compreensão e de aplicação ${ }^{(7,11)}$. Entre elas, a ideia de o Estado financiar a 'cobertura' de serviços de saúde essenciais, apenas aos grupos populacionais em extrema pobreza, os quais deveriam ser "protegidos financeiramente" não arcando com despesas diretas de saúde ${ }^{(7,9,11,12)}$ Trata-se da conformação de uma "[...] cesta básica de serviços para a população pobre, restando o acesso aos demais serviços de saúde pela via do mercado"(4).

$\mathrm{Na}$ América Latina, essa perspectiva diferencia-se dos Sistemas Nacionais de Saúde do Brasil e de Cuba, cujos modelos de proteção social centram-se na garantia constitucional do acesso público, universal e integral, financiado por impostos e sob a responsabilidade direta do Estado ${ }^{(12-14)}$ Entretanto, no caso brasileiro, a configuração real do SUS, para além de sua dimensão legal, coloca-se, ainda, como um desafio.

Outra proposição, em articulação com a CUS, refere-se à condição de um Sistema público, coexistindo com linhas de força que impulsionam a privatização, mercantilização e empresariamento da saúde pública, a exemplo da Lei $n^{0} 13.097 / 2015$, que assegura o alargamento do setor privado no interior do SUS ${ }^{(4)}$. Compondo essa realidade, há a proliferação da chamada Parceria Público Privada (PPP) ${ }^{(15,16)}$, que possibilita ao Estado o repasse da gestão 
de equipamentos públicos de saúde para institucionalidades diversas, inscritas no âmbito do Direito Privado, como a Organização Social (OS) $)^{(17)}$, institucionalidade híbrida em dinâmica de quase-mercado ${ }^{(18,19)}$

Alerta-se para a ocorrência de dois fenômenos emergentes no Brasil, relativos à implementação da política de saúde, nos últimos vinte e cinco anos: o primeiro, refere-se à descentralização de sua formulação, gestão e desenvolvimento; e o segundo, em efeito do primeiro, diz respeito à ampliação do número e da diversidade de atores envolvidos com a oferta e gestão de serviços, incrementando o papel e a importância de sujeitos e instituições não governamentais e fortalecendo diversos tipos de empresariamento da gestão e da oferta ${ }^{(20)}$.

Diante do exposto, duas questões colocam-se como relevantes para investigação, de modo a problematizar e contribuir na produção real do SUS constitucional, sendo elas norteadoras deste artigo: i) O SUS regionalizado estaria sendo atravessado por iniciativas de gestão potentes à implementação de uma Cobertura Universal de Saúde e à sua privatização, mercantilização e empresariamento? Como? ii) Quais os efeitos dessas iniciativas na produção do direito à saúde, universal e integral?

Delineia-se, então, o objetivo de analisar a regionalização da saúde, com ênfase no uso de diferentes tipos de modalidades de gestão e seus efeitos na garantia do direito à saúde, tomando como referência a regionalização da saúde do Ceará, cuja experiência ${ }^{(5,6)}$ sinaliza para uma forte tradição nessa estratégia e, nela, o trânsito de institucionalidades diversas para a gestão de equipamentos públicos de saúde.

\section{MÉTODOS}

O Estudo é de abordagem qualitativa, compreendendo o qualitativo como uma análise dos sentidos, que se produzem no cotidiano das práticas e das relações intersubjetivas e institucionais, na ordem das intensidades, como processualização da vida, portanto, como experimentação do real e não da sua representação( ${ }^{(21)}$.

Como método adotou-se a cartografia ${ }^{(22,23)}$. O solo de investigação compôs-se por dois momentos metodológicos: i) o primeiro, em camada estadual, mapeando a regionalização do Ceará, por Pesquisa aprovada pelo Edital 03/2012, Programa de Pesquisa para o SUS; ii) o segundo, em camada regional, na RS de Sobral, no Ceará, ancorou-se em Pesquisa de Doutorado(6).

\section{Momento Metodológico um: a regionalização da saúde do Ceará}

O primeiro momento desenvolveu-se entre o início 2013 a junho de 2015, tomando como cenário de investigação a regionalização da saúde do Ceará, cujo desenho organizacional estava, à época, constituído por 22 RS e 05 Macrorregiões de Saúde.

Os dados do estudo foram construídos, especialmente, a partir de discursos de gestores públicos estaduais de saúde, capturados por meio de entrevista ${ }^{(24)}$ e de análise de documentos afins ao tema. A escolha dos gestores de saúde orientou-se por serem, estes, os condutores políticos e técnicos da regionalização da saúde do Ceará, colocando-os como alguns dos "sujeitos do discurso"(25). Os critérios foram: i) experiência vinculada à gestão da regionalização da saúde do Ceará; ii) lotação do profissional na Secretaria da Saúde do Estado do Ceará (SESA) ou nas Coordenadorias Regionais de Saúde (CRES), órgão estaduais de representação nas RS constituídas.

Foram entrevistados 23 gestores, cinco de nível central da SESA e 18 das CRES. As entrevistas foram autorizadas pelos sujeitos, mediante Termo de Consentimento Livre e Esclarecido (TCLE), gravadas e transcritas, conformando o corpo discursivo analisado. Em camada estadual, o estudo foi aprovado pelo Comitê de Ética em Pesquisa (CEP) da Universidade Federal do Ceará (UFC), com Parecer de n¹37.055.

\section{Momento Metodológico Dois: a regionalização da saúde na Região de Saúde de Sobral}

A Região de Sobral é formada por 24 municípios, da zona norte, com uma população regional de 629.957 habitantes. Integra a Macrorregião de Saúde Norte, composta por 55 municípios, juntamente com outras quatro RS. Apresenta uma diversidade de equipamentos de saúde, segundo capacidade instalada, natureza jurídica e modalidade de gestão.

Como campo de estudo, optou-se pela habitação de quatro equipamentos de referência regional, localizados em Sobral: i) Centro de Especialidades Médicas Dr. Aristides Andrade (CEM), gestão direta da Secretaria de Saúde de Sobral; ii) Policlínica Bernardo Félix da Silva (Policlínica), implantada em julho de 2012, sob gestão do CPS da Região; iii) Santa Casa de Misericórdia, sociedade civil sem fins lucrativos, filantrópica; iv) Hospital Regional Norte (HRN), instituído em janeiro de 2013, dirigido pelo Instituto de Saúde e Gestão Hospitalar (ISGH), OS.

Considerando os objetivos deste artigo, deu-se relevo ao campo realizado na Policlínica e no HRN, habitados de fevereiro a setembro de 2016 e de junho a setembro 2016, respectivamente. 
Nesses equipamentos, foram feitas entrevistas ${ }^{(24)}$ com gestores e profissionais de saúde e usuários ou familiar em acompanhamento. Os critérios para a escolha dos entrevistados foram: i) livre consentimento em participar do estudo; ii) sujeitos que estavam nos lugares habitados, ou que estavam em outros espaços institucionais relacionados ao objeto em estudo, especialmente, a SESA, Comissão Intergestores Regional (CIR) e o CPS de Sobral; iii) participação nos processos de cuidado e de gestão regionalizados, seja como gestor, profissional ou usuário/acompanhante.

Aos entrevistados, foi solicitada autorização, mediante TCLE específicos, para gestor, profissional de saúde e usuário/acompanhante. Foram produzidas 36 entrevistas: 14 de gestores, 11 de profissionais e 11 de usuários. Todas as entrevistas foram gravadas e transcritas, compondo os arquivos dos discursos analisados.

Para análise, neste artigo, foram priorizados os discursos dos gestores, profissionais e usuários/acompanhantes da Policlínica de Sobral e do HRN, além de outros vinculados aos municípios, CRES e CPS da Região de Sobral. A eles, foram acrescidos os discursos dos gestores estaduais de saúde, do primeiro momento metodológico. Já as citações literais dos discursos foram identificadas: i) gestor público estadual de saúde do nível central da SESA como GES-NC; ii) gestor público estadual de saúde do nível regional da SESA como GES-NR; iii) gestor estadual de saúde da Região de Sobral como GES-RS; iv) gestor municipal de saúde da Região de Sobral como GMS-RS; v) gestor privado de saúde do HRN como GPS-HRN; v) gestor público regional de saúde do CPS e da Policlínica de Sobral como GRS-CPS; vi) usuário da saúde do HRN como U-HRN.

O estudo, em camada regional, foi aprovado pelo CEP da UFC, com Parecer de $n^{\circ} 1.569 .583$, associado ao Parecer do CEP do ISGH, relacionado ao HRN, de $n^{\circ} 1.602 .828$.

Os discursos capturados, tanto no primeiro como no segundo momento, foram analisados como uma produção histórica "[...] ao mesmo tempo controlada, selecionada, organizada e redistribuída por certo número de procedimentos $[\ldots]^{\text {(26) }}$. Assim, o discurso não se reduziu somente ao "[...] que traduz as lutas ou os sistemas de comunicação, mas aquilo porque, pelo que se luta, o poder do qual nós queremos apoderar`(26). Tratou-se de:

"[...] considerar o discurso como uma série de acontecimentos, de estabelecer e descrever as relações que esses acontecimentos - que podemos chamar de acontecimentos discursivos - mantém com outros acontecimentos que pertencem ao sistema econômico, ou ao campo político, ou às instituições"(27).

Assim, os discursos foram tomados como "acontecimentos discursivos"(26-28), analisados não somente por seus enunciados, mas, também, pelas práticas que o constituem em regularidade e descontinuidade, visibilizando suas condições de existência, mudanças e diferenças. Foram tratados, ainda, como "relações de força" ${ }^{\text {"28,29), }}$ compreendendo que "[...] há milhares e milhares de relações de poder e, por conseguinte, relações de forças de

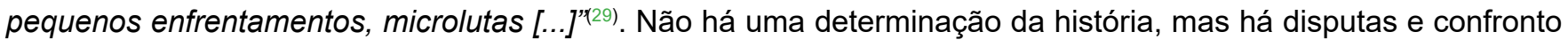
de desejos, projetos políticos e pensamentos, que produzem discursos e práticas.

Dessa forma, pelos sentidos do acontecimento como "discursivo" e como "relações de força", a analítica dos discursos, mapeou a processualidade da regionalização da saúde do Ceará, e de seus efeitos, em aproximação das relações intersubjetivas e institucionais e das modalidades de gestão em uso, tanto em camada estadual como na RS de Sobral.

\section{RESULTADOS E DISCUSSÃO}

\section{Reforma do setor saúde pela estratégia da regionalização: efeitos de uma gestão privatizada?}

No Ceará, a regionalização da saúde, para além de caracterizar o caminho de organização do SUS estadual, configurou-se como estratégia para a reforma estadual do setor da saúde. Reforma, esta, constituída por iniciativas ditas inovadoras, de caráter gerencial e empresarial e por "contratualização de resultados", em associação à Nova Gestão Pública, ou New Public Management ${ }^{(20,30)}$, objetivando tornar o sistema de saúde eficiente, eficaz e de qualidade, mediante a aplicação de uma remodelagem institucional, por meio de mudanças e de ações contínuas e sistemáticas.

Nessa perspectiva, ao longo da década de 90 até os dias atuais, a regionalização foi impulsionada por um largo e potente escopo de ações $(5,6,31)$, destacando-se: i) implantação de novas CRES, seguindo a conformação das RS; ii) ampliação da rede regionalizada pública de saúde, prevendo, em cada Região, o funcionamento de um Centro Especializado Odontológico (CEO), uma Policlínica, com 10 ou 13 especialidades médicas, e, em cada uma das Macrorregiões, um Hospital Regional, tendo sido, até 2016, constituídos 18 CEO, 19 Policlínicas, três Hospitais Regionais; iii) criação de 21 CPS regionais, associação pública de natureza autárquica, formados por entes públicos, estado e municípios, estes últimos segundo cada RS, para a gestão das Policlínicas e CEO construídos; 
iv) qualificação do ISGH, como OS, para a gestão dos Hospitais Regionais e das Unidades de Pronto Atendimento estaduais, localizadas em Fortaleza; v) contratualização, entre os gestores do SUS, do Contrato Organizativo de Ação Pública da Saúde (COAP) ${ }^{(2)}$

Tais iniciativas desenvolveram-se segundo orientações nacionais e estaduais, e por governos sucessivos: Tasso Ribeiro Jereissati (1995-1998; 1999-2002); Lúcio Gonçalo de Alcântara (2003-2006) e Cid Ferreira Gomes (2007-2010; 2011-2014). Nesses governos, aliando o crescimento econômico ao desenvolvimento social, a lógica reformista pautou-se pelo discurso neoliberal, justificando a reforma pela crise do Estado e dos sistemas de proteção social frente à sua própria ineficácia e ineficiência e de suas instituições governamentais.

Os neoliberais consideram que as políticas sociais universalistas e igualitárias, como o SUS, retiram recursos de áreas produtivas para subsidiar e responsabilizar o Estado pela provisão de bens e serviços públicos, como os da saúde, os quais poderiam estar sendo ofertados pelo mercado. Produzem-se, dessa forma, gastos desnecessários e déficit fiscal, além da redução da concorrência no mercado(32).

Nessa linha de argumentação, propõem e articulam um novo modo de organização do Estado, configurando um "Estado-empresário", conforme Fiori discutido por Carvalho ${ }^{(32)}$, apto à correção de ineficiências, disfunções e excesso de burocratização, pela "[...] implementação de um modelo de administração gerencial em que busca transpor para o setor público práticas bem-sucedidas da administração de empresas" (32).

As reformas do Estado, embaladas pelo neoliberalismo, desencadearam um conjunto de mudanças institucionais voltadas para "[...] o desenvolvimento de políticas de reformulação da administração pública [...] os programas massivos de privatização e [...] a revisão das relações entre governos centrais e subnacionais [...]"(20).

No caso do Ceará, a privatização da gestão de equipamentos públicos de saúde recém-criados, teve como marco a Lei estadual $n^{\circ}$ 12.781/1997, que instituiu o Programa Estadual de Incentivo às Organizações Sociais e dispôs sobre a qualificação dessas entidades. Uma decisão política tomada no segundo governo do Senhor Tasso Jereissati, implementada nos anos seguintes, imprimindo um modo de gestão das políticas e dos serviços públicos não restrito à saúde. Entre 1997 a 2017, a referida Lei teve seu artigo $1^{\circ}$ alterado por quatro vezes, ampliando o escopo de atuação das OS, atualmente, relacionado à: assistência social, saúde, trabalho, educação, cultura, turismo, gestão ambiental, habitação, ciência e tecnologia, agricultura, organização agrária, urbanismo, saneamento, desporto e lazer e atendimento ou promoção dos direitos de crianças e adolescentes ${ }^{(6)}$.

Em 2016, a SESA e o ISGH, celebraram Contratos de Gestão para o gerenciamento e execução, pelo Contratado, de atividades e serviços de saúde desenvolvidos pelo Hospital Geral Dr. Waldemar de Alcântara, contratualizado em 2002; por seis UPAS, com quatro Contratos iniciados em 2012 e dois em 2013; por três Hospitais Regionais, referência nas Macrorregiões do Cariri, de Sobral e do Sertão Central, com Contratos começados em 2011, 2013 e 2016, respectivamente. Em 2016, esses Contratos de Gestão e seus Aditivos, em valores financeiros contratados, corresponderam à aproximadamente $19 \%$ do orçamento estadual da saúde, aprovado pela Assembleia Legislativa do Estado do Ceará para o mesmo ano( ${ }^{(6)}$. Algo bastante expressivo que reverbera a escolha governamental pela privatização da gestão de equipamentos públicos de saúde.

Os Contratos de Gestão funcionam como um instrumento legal que expressa os "[...] compromissos gerenciais entre o governo e a diretoria de uma empresa ou setor estatal, com objetivos e metas periódicas, cuja supervisão é realizada pelo Estado"(30). Seu uso é recomendado pelo Banco Mundial, que orienta e induz os gestores públicos para o foco em objetivos específicos e resultados mensuráveis. Refere-se a um instrumento que viabiliza a "contratualização de resultados", aplicada pela Nova Gestão Pública ${ }^{(30)}$.

Nesse sentido, estaria a "contratualização de resultados", uma tecnologia para governar, tensionando a universalidade do acesso e a integralidade em saúde, em esboço de uma "Cobertura Universal"?

\section{O que pode um Contrato de Gestão? Em cena a experiência do Hospital Regional Norte.}

A "contratualização de resultados" e a negociação dos serviços de saúde disponibilizados pelo HRN, conforme o estudo, não passaram nem pelo gestor municipal de Sobral, legalmente considerado gestor pleno do Sistema, nem por nenhum outro das Regiões da Macrorregião Norte, com destaque para a CIR de Sobral, ficando restrita ao nível central da SESA e ao ISGH-HRN.

Assim, o HRN:

"[...] não está dentro do SUS de Sobral" (GMS-RS), operando "[...] de uma forma diferente [...] do que a gente estava acostumada. Então, eles estiveram aqui [citando uma reunião da CIR de Sobral] e depois não retornaram". (GMS-RS). 
Um dos grandes problemas de acesso, nessa Macrorregião, relacionava-se aos serviços de obstetrícia, cuja "porta aberta", para situações de urgência e emergência, limitava-se à Santa Casa de Sobral, configurando "[...] um nó, que a gente tem [...] ela [Santa Casa] superlota a obstetrícia e, realmente, é um caos" (GES-RS):

"São acordos políticos, mesmo, que são feitos. O Hospital Regional ele só recebe paciente referenciado, se for para obstetrícia, embora ele seja porta aberta para outras especialidades, por exemplo, pediatria, [...] mas é muito difícil para obstetrícia porque só recebe os pacientes referenciados [...] Então, assim, eles [HRN] são muito rígidos com os protocolos, por isso, é muito difícil a referência para eles. [...] além de decisões políticas [...] falam que não têm condições de ter o financeiro para manter porta aberta". (GES-RS).

Mesmo diante da extrema necessidade regional e macrorregional de atendimento à gestante, o ISGH-HRN manteve suas portas fechadas para a emergência obstétrica. Sua atuação foi a de uma unidade de retaguarda para a Policlínica e Santa Casa, sinalizando não ser a CIR a instância de pactuação das questões desse equipamento e apontando que os termos do Contrato de Gestão estavam condicionados à "disponibilidade financeira e aos acordos políticos", além do uso "rígido" de protocolos clínicos e de gerenciamento de serviços.

O estudo mapeou, ainda, as restrições do HRN à oferta ambulatorial eletiva, como "primeira consulta". Em decorrência das demandas das emergências adulta e pediátrica, a agenda de pacientes egressos consumiu parte expressiva da oferta disponibilizada para novos pacientes. Assim, ao final de 2014 e início de 2015, houve a redução das consultas ambulatoriais de "pacientes externos", ficando:

"[...] muito mais de pacientes egressos, que já estiveram internados aqui e continuam o segmento ou pósoperatório ou pós uma internação ambulatorial [...]" (GPS-HRN).

Dessa forma, pelas negociações entre a SESA e o ISGH, o HRN prestou atendimento ambulatorial eletivo, prioritariamente, às demandas dos pacientes internos e egressos, esboçando um 'padrão de cobertura', 'mais integralizado' aos que entraram em sua rede, porém, afunilado ao ingresso de novos. A inclusão de alguns pela exclusão de outros. Para os incluídos, o atendimento é:

“[...] muito bom [...] Eu estou com quarenta e cinco anos e eu nunca vi um hospital tão bem equipado, como esse hospital daqui, é a primeira vez [...] a limpeza nota dez e tudo aqui é nota dez" (U-HRN); "[...] minha população fala bem, depois que a pessoa consegue entrar é bem atendido, mas a dificuldade é para entrar [...". (GMS-RS).

Em que pese tal positividade, a problematização, ainda posta, seria a de que a "contratualização de resultados" estaria autorizando a restrição da oferta de serviços, seja pelo afunilamento das "primeiras consultas" ou pela "porta fechada' da emergência obstétrica, compondo um 'gerencialismo controlado' do acesso, mediante a constituição de relações de saber-poder ${ }^{(28,29)}$.

Relações de saber-poder, manifestas em práticas de gestão, que associaram os saberes da Nova Gestão Pública aos saberes médicos, aplicados ao controle de qualidade, segurança do paciente, protocolos clínicos e de gerenciamento de serviços, além das regras contratuais. Constituiu-se, assim, um regime disciplinar e regulamentador das relações e dos modos de organização e funcionamento das instituições e dos sujeitos. O exercício do poder foi mantido e aceito, dado que "[...] não pesa só como uma força que diz não, mas que de fato ele permeia, produz coisas, induz ao prazer, forma saber, produz discurso [...] uma rede produtiva que atravessa todo o corpo social [...]"(33).

Houve, dessa forma, uma intensa e permanente produção de subjetividades, que não só aprovaram os serviços prestados, onde "tudo aqui é nota dez" e "depois que a pessoa consegue entrar é bem atendido", como desejaram tal controle para se sentirem seguras. Mesmo sob a pressão do gerencialismo do acesso, que estreitou, selecionou e cobriu parcela da população, os acordos do Contrato de Gestão foram naturalizados e institucionalizados.

Tratou-se, pelo Contrato de Gestão, de viabilizar a produção de um "regime de verdade", que pôs em relação o saber e o poder, a verdade e o poder, em perspectiva foucaultiana ${ }^{(29)}$ :

"A verdade é deste mundo; ela é produzida nele graças a múltiplas coerções e nele produz efeitos regulamentados de poder. Cada sociedade tem seu regime de verdade, sua "política geral" de verdade: isto é, os tipos de discurso que ela acolhe e faz funcionar como verdadeiros; os mecanismos e as instâncias que permitem distinguir os enunciados verdadeiros dos falsos, a maneira como se sanciona uns e outros; as técnicas e os procedimentos que são valorizados para a obtenção da verdade; o estatuto daqueles que têm o encargo de dizer o que funciona como verdadeiro"(33) 
Nesse sentido, as regras, normas, procedimentos e técnicas, que constituíram a "contratualização de resultados" do HRN, ainda que restritiva, foi adotada pelos gestores do SUS, operada pelos profissionais de saúde e acatada pela sociedade. $\mathrm{O}$ afunilamento de serviços, contratualizado e juridicamente certificado pelo Estado, vem sendo processado (im)pondo verdade, fluxo de funcionamento e de velocidade ao SUS que 'cobre' e não ao SUS que universaliza.

\section{O regime contratual do Consórcio Público de Saúde da Policlínica de Sobral: "uma vaga por mês é uma coisa que tem que sair escolhendo quem vai mandar"}

No Ceará, os CPS instituíram dois tipos de Contratos, o de Rateio e o de Programa. O de Rateio refere-se ao financiamento custeado por cada município. Já o de Programa, à oferta programada das ações e serviços de saúde, especificando, pelo uso da Programação Pactuada Consorcial (PPC), a cota de procedimentos pertinente a cada município.

Assim, mensalmente, a Policlínica de Sobral atualiza a programação de cada especialidade e serviço de saúde, segundo a capacidade de oferta a ser operada no mês subsequente. O cálculo da oferta das consultas médicas por especialidade é feito:

\section{“[... considerando a carga horária do médico e o tempo do procedimento [...]”. (GRS-CPS)}

Nesse sentido, a oferta vem sendo produzida pela disponibilidade médica e capacidade instalada e não pelas necessidades de saúde existentes na Região, configurando a fabricação de necessidades, segundo perfil de oferta proposto. Como efeito, tem-se a programação de uma possível cobertura assistencial, restrita à quantitativos e seletiva à tipos de serviços contratualizados. No caso do acompanhamento à gestante de risco, pela Policlínica de Sobral, o gestor municipal informou que:

"[...] muitas vezes, eu fico ligando [...], por favor, me arranje mais uma vaga, fora da minha que está marcada [...], assim, às vezes eu consigo [...] Mas, uma vaga por mês é uma coisa que tem que sair escolhendo quem vai mandar". (GMS-RS)

Em outro discurso, a perspectiva mercadológica-empresarial perpassou às práticas de saúde. A orientação era para a aquisição de um colete ortopédico, que o pai deveria comprar para o filho, sinalizando que a produção da doença-saúde não se desassocia das relações comerciais. Para isso, compondo a 'prescrição médica', houve a indicação:

“[... leve quinhentos reais que o aparelho é quinhentos reais lá na [...], quando ele chegou na [...], quinhentos reais eram só para segurar o aparelho, o aparelho era mil reais e ele [o comerciante] fazia por novecentos e cinquenta e mandou o orçamento para prefeitura e a prefeitura teve que se virar, sendo que o estado [governo estadual] dá o colete [...] Porque o médico que atende dentro do SUS [...] ele ainda vai mandar para o consultório particular, e mais, ele ainda disse para o pai do menino, que se com uma semana não tivesse com o colete, o menino iria ficar deficiente, que é para família ficar louca, arrumar dinheiro e comprar o aparelho ou, então, botar o prefeito na justiça". (GMS-RS)

O discurso médico acoplou-se às regras do mercado, potencializando a mercadorização da saúde, enquanto objeto de consumo, e institucionalizando-a na produção do SUS, impondo-a como verdadeira pelo saber-poder médico. Diante da finitude fabricada pelo Sistema, sua face perversa, constituiu orientações e agenciamentos múltiplos, onde "[...] as aspirações dos indivíduos não são levadas em conta, são desprezadas, e os indivíduos são vitimas potenciais dos rigores burocráticos e de determinações puramente econômicas"(34).

Em relação ao Contrato de Rateio, o valor rateado entre os municípios, regra geral, corresponde à $60 \%$ do custeio total e o governo estadual aporta $40 \%$. O critério para definição da cota financeira dos entes municipais, frente ao total de custeio da unidade, corresponde ao percentual populacional de cada um em relação à população total de cada RS.

O estudo apontou que a assinatura do Contrato de Rateio compôs uma dupla função. A primeira, referiu-se à responsabilização do prefeito pela contrapartida municipal; e a segunda, a autorização de desconto automático do Imposto sobre Circulação de Mercadorias e Serviços (ICMS), equivalente ao valor municipal contratualizado no CPS. Houve, assim, a instituição de uma forma legal e sistemática de financiamento das ações e serviços de saúde especializados. E isso, sem a possibilidade de inadimplência, considerando o desconto automático. 
Ao estabelecer sua cota-rateio, cada município definiu, também, sua cota-procedimento. Uma matemática assistencial que associou o Contrato de Programa ao de Rateio, imprimindo um padrão de cobertura à Policlínica e seus usuários e regularidade às práticas de gestão contratualizadas, com efeitos restritivos e seletivos, também praticados pelo CPS.

Os regimes contratuais, operados no Ceará, cumpriu o papel de regulamentar as responsabilidades de gestão, investimento, financiamento e manutenção dos novos equipamentos regionalizados, à princípio, sem delegação de mando, dado o desenho federalista brasileiro. Se havia um vazio quanto à autoridade sanitária para assumir tais responsabilidades, as institucionalidades da OS e dos CPS responderam à essa questão, ainda hoje, um desafio na agenda política dos gestores do SUS frente à centralidade da regionalização da saúde ${ }^{(1,4,5,35)}$.

Por outro lado, os regimes contratuais adotados sugeriram escolhas de modalidades de gestão onde, talvez, não "caibam o SUS"(4), público, universal e integral, embora suas razões de existência sejam justificadas e contextualizadas pelo compromisso no seu desenvolvimento.

\section{CONSIDERAÇÕES FINAIS}

O estudo sinalizou a ênfase no regime contratual de serviços de saúde, praticados junto ao CPS e a OS, em fortalecimento de um governo do SUS operado pela conexão das dimensões jurídica à assistencial, imprimindo aos acordos contratualizados o sentido de verdade, dado sua forma legal e sua produção mediante a aplicação de normas e saberes técnicos diversos. Como verdadeiros, os acordos contratualizados, ainda que questionados, deveriam ser realizados.

Houve, assim, a institucionalização do acesso restrito e seletivo, (im)posto pelos Contratos em uso, devidamente autorizados pelo Estado. Pelas regras contratuais, houve a organização contratualizada do que seria direito à saúde, circunscrito ao cálculo financeiro do factível, mediante o gerencialismo econômico e assistencial das ofertas de serviços existentes, efetivamente, não correspondentes às necessidades reais de saúde. Portanto, um exercício de direito à saúde restrito ao contratado, regulado e pago.

Dessa forma, pelo acoplamento da contratualização à regionalização, a reforma do setor saúde do Ceará tem se constituído como um cenário profícuo à modelagem do SUS travestido pela Cobertura Universal de Saúde, institucionalizando o deslocamento do SUS integral e universal para o SUS parcial e focal; de um SUS público para o SUS que privatiza a gestão de seus equipamentos, mercantiliza a saúde como bem de consumo e não de direito social e empresaria os modos de sua produção.

Em pese a positividade da ampliação da capacidade de oferta, os acontecimentos discursivos e as relações de força cartografados reverberam a invisibilidade da universidade do acesso e da integralidade da atenção à saúde, atualizando os desafios da gestão do SUS em modos contratualizados e regionalizados.

Baseado em Tese: Regionalização da Saúde: cartografia dos modos de produção do cuidado e de gestão em saúde. Universidade Federal do Ceará, Faculdade de Medicina, Departamento de Saúde Comunitária, Programa de Pós-graduação em Saúde Coletiva, Fortaleza, 2017, 446 p.

\section{REFERÊNCIAS}

1. Santos L, Campos GWS. SUS Brasil: a região de saúde como o caminho. Saúde Soc. [Internet]. 2015 [acesso em 2015 Jul 15]; 24(2):438-46. Disponível em: http://www.scielo.br/pdf/sausoc/v24n2/0104-1290-sausoc-24-02-00438. pdf.

2. Brasil. Decreto n. 7.508, de 29 de Junho de 2011. Regulamenta a Lei n. 8.080/90, para dispor sobre a organização do SUS, o planejamento da saúde, a assistência à saúde e a articulação interfederativa, e dá outras providências [Internet]. Diário Oficial da República Federativa do Brasil, Brasília. 2011. [acesso em 2012 Abr 10]. Disponível em: http://www.planalto.gov.br/ccivil_03/_ato2011-2014/2011/decreto/D7508.htm.

3. Mattos RA. A integralidade na prática (ou sobre a prática da integralidade). Cad Saúde Pública [Internet]. 2004 [acesso em 2012 Ago 08];20(5):1411-6. Disponível em: http://www.scielo.br/scielo.php?script=sci_ arttext\&pid=S0102-311X2004000500037.

4. Mendes A, Louvison M. O debate da regionalização em tempos de turbulência no SUS. Saude Soc. [Internet]. 2015 [acesso em 2015 Jul 15];24(2):393-7. Disponível em: http://www.scielo.br/scielo.php?pid=S0104$12902015000200393 \&$ script=sci_arttext. 
5. Goya N, Andrade LOM, Pontes RJS, Tajra FS. Regionalização da saúde: (in)visibilidade e (i)materialidade da universalidade e integralidade em saúde no trânsito de institucionalidades. Saude Soc. [Internet]. 2016 [acesso em 2017 Jan 13];25(4):902-19. Disponível em: http://www.scielo.br/scielo.php?pid=S0104$12902016000400902 \&$ script=sci_abstract\&tIng=pt.

6. Goya N. Regionalização da saúde: cartografia dos modos de produção do cuidado e de gestão em saúde [tese]. Fortaleza: Universidade Federal do Ceará; 2017.

7. Noronha JC. Cobertura universal de saúde: como misturar conceitos, confundir objetivos, abandonar princípios. Cad Saúde Pública [Internet]. 2013 [acesso em 2017 Nov 29];29(5):847-9. Disponível em: http://www.scielo.br/ scielo.php?script=sci_arttext\&pid=S0102-311X2013000500003.

8. Horton R, Das P. Universal health coverage: not why, what, or when—but how? The Lancet [Internet]. 2015 [acesso em 2017 Dez 09];385(9974):1156-7. Disponível em: http://www.thelancet.com/journals/lancet/article/ PIIS0140-6736(14)61742-6/fulltext.

9. Barros FPC, Delduque MC, Santos AOS. O direito à saúde e a proposta de cobertura universal. Consensus [Internet]. 2016 [acesso em 2017 Dez 07];VI(19):44-9. Disponível em: http://www.conass.org.br/biblioteca/pdf/ revistaconsensus_19.pdf.

10. Etienne CF. Achieving universal health coverage is a moral imperative. The Lancet [Internet]. 2015 [acesso em 2017 Dec 07];385(9975):1271-3. Disponível em: http://www.thelancet.com/journals/lancet/article/PIIS01406736(14)61679-2/fulltext.

11. Antunes A, Mathia M. Cobertura Universal de Saúde, a nova aposta do capital [Internet]. 2014 [acesso em 2017 Dez 10]. Disponível em: http://cebes.org.br/2014/12/cobertura-universal-de-saude-a-nova-aposta-do-capital/.

12. Heredia N, Laurell AC, Feo O, Noronha J, González-Guzmán R, Torres-Tovar M. The right to health: what model for Latin America? The Lancet [Internet]. [acesso em 2017 Dec 07];385(9975):e34-7. Disponível em: http://www. thelancet.com/pdfs/journals/lancet/PIIS0140-6736(14)61493-8.pdf.

13. Atun R, Andrade LOM, Almeida G, Cotlear D, Dmytraczenko T, Frenz P; et al. Health-system reform and universal health coverage in Latin America. The Lancet [Internet]. [acesso em 2017 Dec 9];385(9974):1230-47. Disponível em: http://www.thelancet.com/journals/lancet/article/PIIS0140-6736(14)61646-9/fulltext.

14. Andrade LOM, Pellegrini Filho A, Solar O, Rígoli F, Salazar LM, Pastor Serrate C-F; et al. Social determinants of health, universal health coverage, and sustainable development: case studies from Latin American countries. The Lancet [Internet]. [acesso em 2017 Dec 7];385(9975):1343-51. Disponível em: http://www.thelancet.com/ journals/lancet/article/PIIS0140-6736(14)61494-X/fulltext.

15. Almeida C. Parcerias público-privadas (PPP) no setor saúde: processos globais e dinâmicas nacionais. Cad Saúde Pública [Internet]. 2017 [acesso em 2017 Dez 18];33(Suppl2):e00197316. Disponível em: http://www. scielo.br/pdf/csp/v33s2/1678-4464-csp-33-s2-e00197316.pdf.

16. Barbosa AP, Malik AM. Desafios na organização de parcerias público-privadas em saúde no Brasil. Análise de projetos estruturados entre janeiro de 2010 e março de 2014. Rev Adm Pública [Internet]. 2015 [acesso em 2017 Dez 18];49(5):1143-65. Disponível em: http://www.scielo.br/pdf/rap/v49n5/0034-7612-rap-49-05-01143.pdf.

17. Contreiras H, Matta GC. Privatização da gestão do sistema municipal de saúde por meio de Organizações Sociais na cidade de São Paulo, Brasil: caracterização e análise da regulação. Cad Saúde Pública [Internet]. 2015;31(2):285-97.

18. Costa NR, Ribeiro JM, Silva PLB. A experiência internacional de reforma do setor saúde: inovações organizacionais e de financiamento. Rev Adm Pública [Internet]. 2000 [acesso em 2015 Abr 2];34(1):209-27. Disponível em: http://bibliotecadigital.fgv.br/ojs/index.php/rap/article/view/6259.

19. Miranda AS. Pluralismo agenciado da política e gestão pública de saúde em institucionalidade híbrida e dinâmica de (quase) mercado [Internet]. 2013 [acesso em 2014 Abr 04]. Disponível em: http://cebes.org.br/2013/07/ pluralismo-agenciado-da-politica-e-gestao-publicas-de-saude-em-institucionalidade-hibrida-e-dinamicas-dequasemercado/.

20. Viana ALA, Miranda AS, Silva HP. Segmentos institucionais de gestão em saúde: descrição, tendências e cenários prospectivos [Internet]. 2015 [acesso em 2015 Abr 04]. Disponível em: https://saudeamanha.fiocruz. 
br/wp-content/uploads/2016/07/2-PJSSaudeAmanha_Texto0002_final.pdf.

21. Rocha ML, Aguiar KF. Pesquisa-intervenção e a produção de novas análises. Psicol Ciênc Prof. 2003;23(4): 64-73.

22. Passos E, Kastrup V, Escóssia L. Pistas do método da cartografia: pesquisa-intervenção e produção de subjetividade. Porto Alegre: Sulina; 2015.

23. Martines WRV, Machado AL, Covero LA. A cartografia como inovação metodológica na pesquisa em saúde. Tempus [Internet]. 2013 [acesso em 2014 Nov 12];7(2):203-11. Disponível em: http://www.tempusactas.unb.br/ index.php/tempus/article/view/1354/1158.

24. Tedesco SH, Sade C, Caliman LV. A entrevista na pesquisa cartográfica: a experiência do dizer. Fractal Rev Psicol. [Internet]. 2013 [acesso em 2015 Mar 12];25(2):299-322. Disponível em: http://www.scielo.br/scielo. php?script=sci_arttext\&pid=S1984-02922013000200006.

25. Araújo IL. Formação discursiva como conceito chave para a arqueogenealogia de Foucault. Revista Aulas [Internet]. 2007 [acesso em 2015 Set 03];3:1-24. Disponível em: http://www.ifch.unicamp.br/ojs/index.php/aulas/ article/viewFile/1924/1385.

26. Foucault M. A ordem do discurso: aula inaugural do Collège de France. São Paulo: Edições Loyola; 2014.

27. Foucault M. Diálogo sobre o Poder. In: Motta MB, organizador. Ditos e escritos IV. Rio de Janeiro: Forense Universitária; 2006. p. 253-69.

28. Castro E. Vocabulário de Foucault: um percurso pelos seus temas, conceitos e autores. Belo Horizonte: Autêntica; 2016.

29. Foucault M. Poder e Saber. In: Motta MB, organizador. Ditos e escritos IV. Rio de Janeiro: Forense Universitária; 2006. p. 223-40.

30. Ditterich RG, Moysés ST, Moysés SJ. O uso de contratos de gestão e incentivos profissionais no setor público de saúde. Cad Saúde Pública [Internet]. 2012 [acesso em 2017 Dez 12];28(4):615-27. Disponível em: http:// www.scielo.br/pdf/csp/v28n4/02.pdf.

31. Goya N, Andrade LOM, Pontes RJS, Tajra FS, Barreto ICHC. Percepções de gestores estaduais da saúde sobre o Contrato Organizativo da Ação Pública da Saúde no Ceará, Brasil. Ciênc Saúde Colet. 2017;22(4):1235-44.

32. Carvalho SR. Reflexões sobre o tema da cidadania e a produção de subjetividade no SUS. In: Carvalho SR, Ferigato S, Barros ME, organizadores. Conexões: saúde coletiva e políticas da subjetividade. São Paulo: Aderaldo Rothschild; 2009. p. 23-41.

33. Foucault M. Verdade e Poder. In: Machado R. Microfísica do poder. Rio de Janeiro: Graal; 1990. p. 4-11.

34. Branco GC. A seguridade social em Michel Foucault. Ecopolítica [Internet]. 2013 [acesso em 2015 Ago 14];(5):7689. Disponível em: https://revistas.pucsp.br/index.php/ecopolitica/article/view/14985.

35. Shimizu HE. Percepção dos gestores do Sistema Único de Saúde acerca dos desafios da formação das redes de atenção à saúde no Brasil. Physis [Internet]. 2013 [acesso em 2014 Jun 10];23(4):1101-22. Disponível em: http://www.scielo.br/scielo.php?script=sci_arttext\&pid=S0103-73312013000400005\&lng=en\&nrm=iso.

\section{Endereço para correspondência:}

Neusa Goya

Avenida Rogaciano Leite, 200/703

CEP: 60.810-786 - Fortaleza - CE - Brasil

E-mail: neusagoya@gmail.com 